\title{
Replacing ground corn with incremental amounts of liquid molasses does not change milk enterolactone but decreases production in dairy cows fed flaxseed meal
}

\author{
C. P. Ghedini, ${ }^{*}$ D. C. Moura, $\dagger$ R. A. V. Santana, $\ddagger$ A. S. Oliveira, $\dagger$ and A. F. Brito*1 \\ *Department of Agriculture, Nutrition, and Food Systems, University of New Hampshire, Durham 03824 \\ †Instituto de Ciências Agrárias e Ambientais, Universidade Federal de Mato Grosso - Campus Sinop, Sinop, MT, Brazil 78557-267 \\ łlnstituto Federal de Educação, Ciência e Tecnologia do Norte de Minas Gerais - Campus Arinos, Arinos, MG, Brazil 38680-000
}

\begin{abstract}
We investigated the effects of replacing ground corn (GRC) with incremental amounts of liquid molasses (LM) on milk enterolactone concentration, antioxidant enzymes activity in plasma, production, milk fatty acid (FA) profile, and nutrient utilization in Jersey cows fed flaxseed meal and low-starch diets. Sixteen multiparous organically certified Jersey cows averaging (mean \pm standard deviation) $101 \pm 45 \mathrm{~d}$ in milk, $462 \pm 38 \mathrm{~kg}$ of body weight, and $19.8 \pm 3.90 \mathrm{~kg} / \mathrm{d}$ of milk in the beginning of the study were randomly assigned to treatment sequences in a replicated $4 \times 4$ Latin square design, with $14 \mathrm{~d}$ for diet adaptation and $7 \mathrm{~d}$ for data and sample collection. Diets were fed as total mixed rations consisting (dry matter basis) of $52 \%$ grass-legume baleage, $8 \%$ grass hay, $8.5 \%$ soyhulls, $2.5 \%$ roasted soybean, $15 \%$ flaxseed meal, and $2 \%$ minerals-vitamins premix. The GRC-to-LM dietary ratios (dry matter basis) were 12:0, 8:4, 4:8, and 0:12. Orthogonal polynomials were used to test linear, quadratic, and cubic effects using the MIXED procedure of SAS (SAS Institute Inc., Cary, NC). The milk concentration of enterolactone tended to respond cubically, thus suggesting that replacing GRC with LM did not affect this lignan in milk. The plasma activities of the antioxidant enzymes glutathione peroxidase and catalase did not differ, but superoxide dismutase activity tended to respond cubically with feeding increasing amounts of LM. Dry matter intake and yields of milk and milk fat, true protein, and lactose decreased linearly with substituting GRC for LM. Whereas the concentrations of milk fat and milk true protein did not differ across treatments, milk lactose content decreased linearly. Feeding incremental levels of LM reduced linearly the milk concentration of urea $\mathrm{N}$ and the amount of $\mathrm{N}$ excreted in urine, and
\end{abstract}

Received August 15, 2017.

Accepted November 1, 2017.

${ }^{1}$ Corresponding author: andre.brito@unh.edu tended to decrease linearly the concentration of plasma urea N. Apparent total-tract digestibilities of dry matter, organic matter, and neutral and acid detergent fiber did not differ across treatments, whereas digestibility of crude protein decreased linearly. Digestibility of starch responded linearly and quadratically, but the actual differences between treatments were too small to be biologically significant. Milk FA profile was substantially changed most notably by linear increases in cis-9,trans-11 18:2, cis-9, cis-12,cis-15 18:3, $\Sigma$ odd-chain FA, and the trans-11-to-trans-10 ratio, and linear decreases in cis-9 18:1 and cis-9,cis-12 18:2 when replacing GRC by incremental amounts of LM.

Key words: antioxidant, lignan, organic dairy, public health

\section{INTRODUCTION}

Lignans are polyphenolic, phytoestrogenic compounds known to elicit a wide range of biological activities, including weak estrogenic and cardioprotective effects, as well as antiestrogenic, antioxidant, anti-inflammatory, and anticarcinogenic properties (Adolphe et al., 2010; Högger, 2013; Imran et al., 2015). Flaxseed (Linum usitatissimum L.) is the richest source of the lignan secoisolariciresinol diglucoside (SDG), which is a precursor for the synthesis of the mammalian lignans enterolactone (EL) and enterodiol by the gut microbiota of humans (Thompson et al., 1991; Gaya et al., 2016) and ruminants (Gagnon et al., 2009; Zhou et al., 2009). Feeding incremental amounts of flaxseed meal (FM) to dairy cows increased linearly the milk concentration of EL, whereas no enterodiol was detected in milk (Petit and Gagnon, 2009). Recently, we reported that the concentration of EL in milk was modified by the type of NSC source supplemented to dairy cows fed diets containing (DM basis) 15\% FM, with liquid molasses (LM) leading to greater milk EL than ground corn (GRC; Brito et al., 2015). This suggests that, compared with GRC, LM may select for ruminal mi- 
croorganisms with better capacity to convert FM-SDG to EL. However, we are not aware of any study to date that has investigated whether milk EL concentration behaves in a linear or curvilinear fashion in response to incremental amounts of LM in cows offered FM. There is also lack of information regarding whether LM could interact synergistically with GRC to maximize the concentration of EL in milk.

There has been a continuous interest in the use of sugarcane molasses in both conventional (Broderick and Radloff, 2004; Martel et al., 2011; Siverson et al., 2014) and organic (Soder et al., 2012; Brito et al., 2015, 2017) dairy systems in the United States. Whereas conventional dairy cows have been fed dried molasses or LM accompanied by other NSC supplements and corn silage (Broderick and Radloff, 2004; Martel et al., 2011; Siverson et al., 2014), organically certified dairy cows are typically fed LM as the sole NSC supplemental source to grass hay (Brito et al., 2015) or mixed grass-legume pasture (Soder et al., 2012; Brito et al., 2017). Previous dose-response studies resulted in inconsistent responses on DMI, milk yield and composition, and nutrient digestibility when dried or LM partially replaced high-moisture corn (Broderick and Radloff, 2004; Baurhoo and Mustafa, 2014) or GRC (Martel et al., 2011) in moderate- to high-starch diets. However, research addressing the effect of completely replacing GRC with incremental amounts of LM on production, milk composition, and nutrient utilization in dairy cows fed mixed grass-legume baleage and low-starch diets is lacking.

We hypothesized that (1) the concentration of EL in milk would be modulated by expected changes in DM and SDG intakes when replacing GRC with incremental amounts of LM in cows fed FM. We also hypothesized that replacing GRC with LM would lead to (2) increased milk yield and milk $\mathrm{N}$ efficiency (i.e., milk $\mathrm{N} / \mathrm{N}$ intake) due to improved balance between RDP and fermentable energy supply, as sucrose from LM is more rapidly degraded in the rumen than starch from GRC; and (3) marked changes in milk fatty acid (FA) profile in response to expected differences in 18C FA intake between GRC and LM. The objective of our study was to evaluate the effects of replacing GRC with incremental amounts of LM on milk EL concentration, antioxidant enzymes activity in plasma, production, milk FA profile, and apparent total-tract digestibility of nutrients in Jersey cows fed FM and low-starch diets.

\section{MATERIALS AND METHODS}

This 84-d long study was conducted at the University of New Hampshire Burley-Demeritt Organic Dairy Re- search Farm $\left(43^{\circ} 10^{\prime} \mathrm{N}, 70^{\circ} 99^{\prime} \mathrm{W}\right.$; Lee, NH) from December 3, 2014, to February 24, 2015. Care and handling of cows used in our study were conducted as outlined in the guidelines of the University of New Hampshire Institutional Animal Care and Use Committee (IACUC Protocol \#140901).

\section{Cows, Experimental Design, and Diets}

Sixteen multiparous organically certified Jersey cows averaging (mean $\pm \mathrm{SD}$ ) $101 \pm 45$ DIM, $462 \pm 38 \mathrm{~kg}$ of BW, and $19.8 \pm 3.90 \mathrm{~kg} / \mathrm{d}$ of milk in the beginning of the study were used. Distribution of cows to squares was done to balance for differences in DIM (square 1 $=163 \pm 10$ DIM; square $2=112 \pm 16$ DIM; square $3=78 \pm 7$ DIM; square $4=50 \pm 10$ DIM). Within each square, cows were randomly assigned to treatment sequences in a replicated $4 \times 4$ Latin square design. Each experimental period lasted $21 \mathrm{~d}$, with $14 \mathrm{~d}$ for diet adaptation and $7 \mathrm{~d}$ for data and sample collection. The experimental diets were fed as TMR consisting (DM basis) of $31.2 \%$ mixed-mostly grass baleage, $20.8 \%$ mixed-mostly legume baleage, $8 \%$ grass hay, $8.5 \%$ soyhulls, $2.5 \%$ roasted soybean, $15 \% \mathrm{FM}$, and $2 \%$ minerals-vitamins premix. The GRC-to-LM dietary ratios (DM basis) were 12:0, 8:4, 4:8, and 0:12. Sugarcane LM was purchased from Buffalo Molasses LCC (North Java, NY). The nutritional composition of the feedstuffs used in this study is presented in Table 1, and the ingredient and nutritional composition of the experimental diets are reported in Table 2.

Cows were housed in a bedded-pack barn with dried pine shavings as bedding and kept in a pen separated from the remaining lactating cows in the herd. The bedding area $\left(132 \mathrm{~m}^{2}\right)$ opens to a $478-\mathrm{m}^{2}$ concrete-floor outdoor lot (total pen area $=610 \mathrm{~m}^{2}$ ), allowing cows to walk freely in compliance with the USDA National Organic Program "Livestock living conditions" (USDA, 2010), which calls for year-round access to the outdoors for all ruminants among other regulations. Cows had access to a roof-covered feeding station equipped with electronic recognition Calan doors system (American Calan Inc., Northwood, NH) located at the end of the pen facing the bedding area.

\section{Feeding Management and Feed Sampling and Analyses}

All bales used in this study were sampled before feeding using a Hilti model TE 7-A drill (Hilti North America, Tulsa, OK) fitted with a 40-cm long metal core sampler. Throughout the study, approximately 150-g forage samples were obtained after 3 to 4 core 


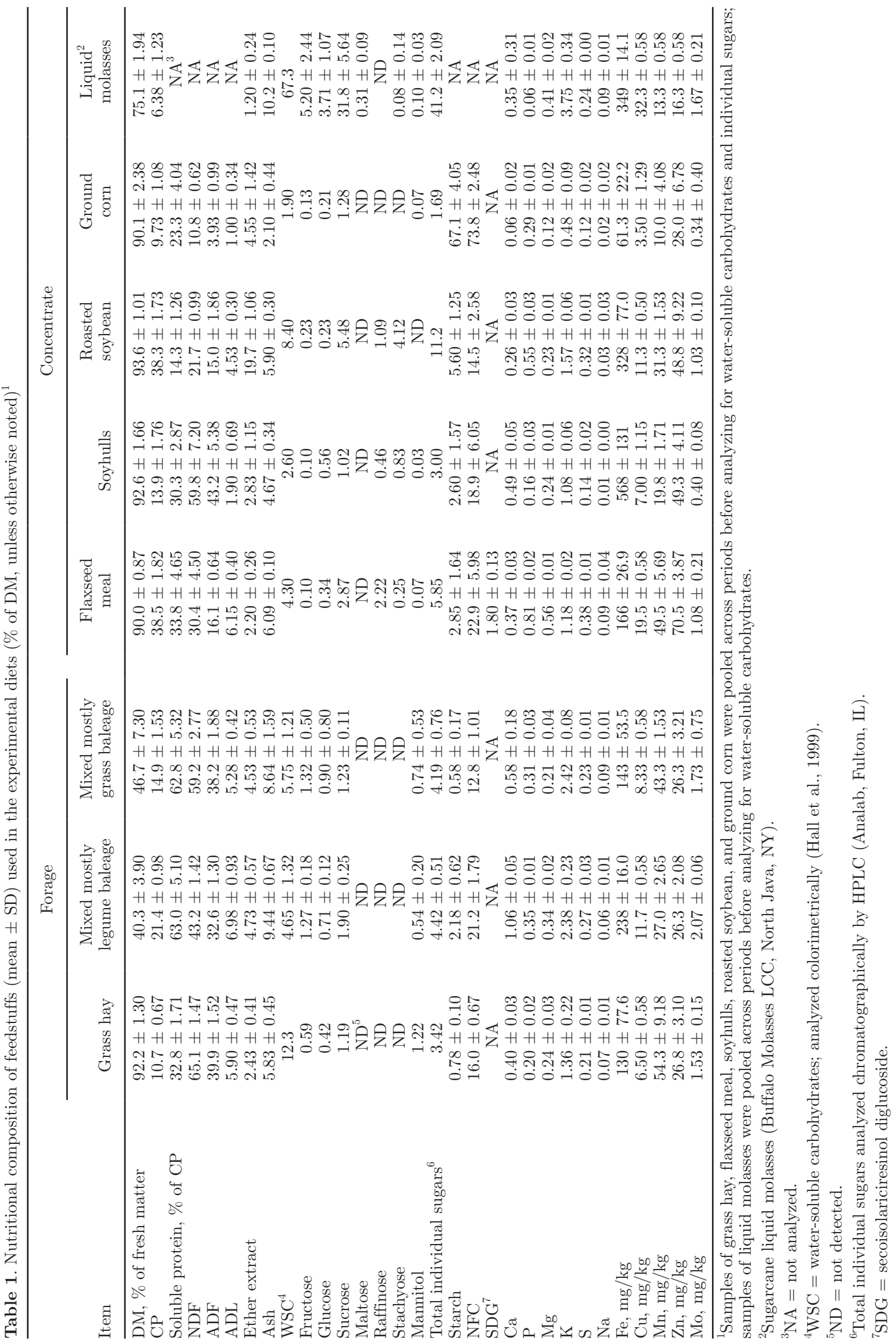


Table 2. Ingredient and nutritional composition (\% of DM, unless otherwise noted) of the experimental diets

\begin{tabular}{|c|c|c|c|c|}
\hline \multirow[b]{2}{*}{ Item } & \multicolumn{4}{|c|}{ Dietary levels of liquid molasses } \\
\hline & $0 \%$ & $4 \%$ & $8 \%$ & $12 \%$ \\
\hline \multicolumn{5}{|l|}{ Ingredient composition } \\
\hline Mixed mostly grass baleage & 31.2 & 31.2 & 31.2 & 31.2 \\
\hline Mixed mostly legume baleage & 20.8 & 20.8 & 20.8 & 20.8 \\
\hline Grass hay & 8.00 & 8.00 & 8.00 & 8.0 \\
\hline Sugarcane liquid molasses & 0.00 & 4.00 & 8.00 & 12.0 \\
\hline Ground corn & 12.0 & 8.00 & 4.00 & 0.00 \\
\hline Flaxseed meal & 15.0 & 15.0 & 15.0 & 15.0 \\
\hline Roasted soybean & 2.50 & 2.50 & 2.50 & 2.50 \\
\hline Soyhulls & 8.50 & 8.50 & 8.50 & 8.50 \\
\hline Minerals-vitamins premix ${ }^{1}$ & 2.00 & 2.00 & 2.00 & 2.00 \\
\hline \multicolumn{5}{|l|}{ Nutritional composition $^{2}$} \\
\hline DM, \% of fresh matter & 52.8 & 50.5 & 50.7 & 50.1 \\
\hline $\mathrm{CP}$ & 19.0 & 18.8 & 18.8 & 18.6 \\
\hline NDF & 44.2 & 43.7 & 43.3 & 42.9 \\
\hline $\mathrm{ADF}$ & 28.8 & 28.7 & 28.5 & 28.3 \\
\hline ADL & 4.89 & 4.85 & 4.81 & 4.77 \\
\hline Starch & 9.53 & 6.85 & 4.16 & 1.48 \\
\hline NFC & 25.8 & 26.2 & 26.7 & 27.0 \\
\hline Total individual sugars added ${ }^{3}$ & 0.00 & 1.65 & 3.30 & 4.95 \\
\hline Total individual sugars ${ }^{4}$ & 3.90 & 5.48 & 7.05 & 8.63 \\
\hline WSC added ${ }^{5}$ & 0.00 & 2.69 & 5.38 & 8.08 \\
\hline Total WSC $\mathrm{WS}^{6}$ & 4.02 & 5.21 & 9.74 & 12.9 \\
\hline Ash & 6.84 & 7.16 & 7.28 & 7.81 \\
\hline Ether extract & 4.20 & 4.06 & 3.93 & 3.79 \\
\hline $\mathrm{Ca}$ & 0.94 & 0.96 & 0.97 & 0.99 \\
\hline $\mathrm{P}$ & 0.39 & 0.36 & 0.37 & 0.34 \\
\hline $\mathrm{K}$ & 1.72 & 1.85 & 1.98 & 2.12 \\
\hline $\mathrm{Na}$ & 0.24 & 0.25 & 0.25 & 0.25 \\
\hline $\mathrm{NE}_{\mathrm{L}},{ }^{7} \mathrm{Mcal} / \mathrm{kg}$ of $\mathrm{DM}$ & 1.57 & 1.56 & 1.56 & 1.56 \\
\hline \multicolumn{5}{|l|}{ Fatty acids, ${ }^{8} \mathrm{~g} / \mathrm{kg}$ of DM } \\
\hline 16:0 & 3.83 & 3.84 & 3.48 & 3.44 \\
\hline 18:0 & 0.74 & 0.76 & 0.68 & 0.69 \\
\hline cis-9 18:1 & 3.10 & 2.93 & 2.49 & 2.42 \\
\hline cis-9,cis-12 18:2 & 6.59 & 6.40 & 5.66 & 5.28 \\
\hline cis-9, cis-12,cis-15 18:3 & 6.72 & 6.76 & 6.69 & 6.78 \\
\hline Others and unidentified & 1.62 & 1.73 & 1.95 & 2.09 \\
\hline Total & 22.6 & 22.4 & 20.9 & 20.7 \\
\hline
\end{tabular}

${ }^{1}$ The minerals and vitamins premix contained (DM basis): $19.9 \% \mathrm{Ca}, 1.11 \% \mathrm{P}, 9.50 \% \mathrm{Mg}, 0.11 \% \mathrm{~K}, 9.19 \% \mathrm{Na}$, $14.1 \% \mathrm{Cl}, 13.6 \mathrm{mg} / \mathrm{kg}$ of Se, $319 \mathrm{mg} / \mathrm{kg}$ of Cu, 2,097 mg/ $\mathrm{kg}$ of Mn, 2,337 mg $/ \mathrm{kg}$ of Zn, $1,624 \mathrm{mg} / \mathrm{kg}$ of Fe, 31.2 $\mathrm{mg} / \mathrm{kg}$ of I, 96,068 IU $/ \mathrm{kg}$ of vitamin A, 22,130 IU $/ \mathrm{kg}$ of vitamin $\mathrm{D}_{3}$, and $513 \mathrm{IU} / \mathrm{kg}$ of vitamin E.

${ }^{2}$ The nutritional composition of the diets was calculated based on the individual nutritional composition of the dietary ingredients as reported in Table 1.

${ }^{3}$ Total individual sugars added from liquid molasses analyzed chromatographically by HPLC (Analab, Fulton, IL).

${ }^{4}$ Dietary total individual sugars (liquid molasses plus remaining feedstuffs) analyzed chromatographically by $\operatorname{HPLC}($ Analab).

${ }^{5}$ Water-soluble carbohydrates (WSC) added from liquid molasses analyzed colorimetrically (Hall et al., 1999).

${ }^{6}$ Total WSC (liquid molasses plus remaining feedstuffs) analyzed colorimetrically (Hall et al., 1999).

${ }^{7}$ Determined using the NRC (2001) using actual feed nutritional composition and animal variables (i.e., DMI, milk yield and composition, DIM, and BW).

${ }^{8}$ Dietary fatty acid profile determined using TMR samples.

samplings from each bale and dried in a forced-air oven set at $55^{\circ} \mathrm{C}$ for approximately $48 \mathrm{~h}$, with the resulting DM used to adjust the daily proportions of forages in the as-fed TMR. Baleage and hay bales were chopped using a TMR vertical mixer (Valmetal V-Mix 400; Saint-Germain-de-Grantham, QC, Canada). All dietary ingredients, including LM, were mixed twice daily using an A100 Self-Propelled mixer (Jaylor Fabricating Inc., East Garafraxa, ON, Canada) and offered to the cows as TMR at 0700 and $1600 \mathrm{~h}$. Approximately $40 \%$ of the daily TMR allocation was offered in the morning and the remaining $60 \%$ in the afternoon to account for uneven intervals between feeding times (i.e., $9 \mathrm{~h}$ between $0700 \mathrm{~h}$ and $1600 \mathrm{~h}$ and $15 \mathrm{~h}$ between $1600 \mathrm{~h}$ and 0700 
h). The amount of each dietary ingredient used to make the TMR was recorded using the A100 Self-Propelled mixer (Jaylor Fabricating Inc.), which is equipped with an electronic scale system (Dinamica Generale US Inc., St. Charles, IL). Refusals were collected daily before the afternoon feeding and weighed as done for the TMR. The amount of TMR offered to the cows was adjusted daily to allow refusals of 5 to $10 \%$ of the as fed intake. The Calan doors system (American Calan Inc.) was used to individualize the dietary treatments, and feed intake was recorded by subtracting the total amount of TMR offered daily from that of refusals. Body weight was measured immediately after the afternoon milking during 3 consecutive days before the beginning of the study and during the last $3 \mathrm{~d}$ of each sampling week to determine BW change.

Samples of TMR, feeds, and refusals (composited by diet) were collected daily during each sampling week, composited by period, dried in a forced-air oven $\left(55^{\circ} \mathrm{C}\right.$, $48 \mathrm{~h}$ ), and ground to pass through a 1-mm screen (Wiley mill; Arthur H. Thomas, Philadelphia, PA). Feeds (baleages, hay, soyhulls, GRC, roasted soybean, soybean meal, and FM) were shipped to a commercial laboratory (Dairy One Cooperative Inc., Ithaca, NY) and analyzed for DM (method 930.15; AOAC International, 2016), total N (method 990.03; AOAC International, 2016), NDF (method 6 in an Ankom ${ }^{200}$ Fiber Analyzer with $\alpha$-amylase and sodium sulfite; Ankom Technology, Fairpoint, NY; solutions as in Van Soest et al., 1991), $\mathrm{ADF}$ [method 5 in an Ankom ${ }^{200}$ Fiber Analyzer; solutions as in method 973.18 (AOAC International, 2016)], ADL [method 9 in a Ankom Daisy Incubator; solutions as in method 973.18 (AOAC International, 2016)], ether extract [extraction by a Soxtec HT6 System (Foss North America, Eden Prairie, MN) using anhydrous diethyl ether; method 2003.05 (AOAC International, 2016)], starch (YSI 2700 Select Biochemistry Analyzer, application note no. 319; YSI Inc. Life Sciences, Yellow Springs, OH), water-soluble carbohydrates (WSC; Hall et al., 1999), and ash (method 942.05; AOAC International, 2016). Liquid molasses was analyzed (Dairy One Cooperative Inc.) for DM, total N, ether extract, ash, and WSC, whereas refusals were analyzed for NDF and $\mathrm{ADF}$ in addition to DM, total $\mathrm{N}$, and ash using the procedures reported above. Individual minerals $(\mathrm{Ca}, \mathrm{P}$, $\mathrm{Mg}, \mathrm{K}, \mathrm{Na}, \mathrm{Fe}, \mathrm{Zn}, \mathrm{Cu}, \mathrm{Mn}, \mathrm{Mo}$, and S) were analyzed (Dairy One Cooperative Inc.) in all feed samples using an iCAP 6300 Intrepid Inductively Coupled Plasma Radial Spectrometer (Thermo Fisher Scientific Inc., Waltham, MA) after microwave digestion (CEM application note (http://dairyone.com/wpcontent/uploads/ 2014/02/Forage-Lab-Analytical-Procedures-Listing -Alphabetical-July2015.pdf) for acid digestion; CEM,
Matthews, NC). All feeds were also analyzed (Analab, Fulton, IL) for individual sugars using a Beckman HPLC (Beckman Coulter Inc., Fullerton, CA) equipped with an evaporative light scattering detection system. Samples of TMR were sent to Pennsylvania State University (University Park; Kevin Harvatine Laboratory) for FA analysis using GLC after direct methylation (Sukhija and Palmquist, 1988). Flaxseed meal samples were shipped to Bioprofile Testing Laboratories (St. Paul, MN) for SDG analysis using HPLC according to the procedures described by Muir and Westcott (2000).

\section{Milk Sampling and Analyses}

Cows were milked twice daily at approximately 0500 and $1530 \mathrm{~h}$ in a 4-stall step-up parlor equipped with headlocks (Agromatic, Fond DuLac, WI), automatic take-offs, and milk meters (Westfalia Surge; GEA Farm Technologies Inc., Naperville, IL). Milk weights were recorded daily throughout the duration of the experiment (DairyPlan C21 Version 5.2; GEA Farm Technologies Inc.). Milk samples were collected during 4 consecutive milkings (d 20 and 21) of each sampling week, stored in tubes containing 2-bromo-2-nitropropan-1,3-diol, pooled by cow according to morning and evening milk weights, and refrigerated at $4^{\circ} \mathrm{C}$ until shipped to Dairy One Cooperative Inc. for determination of fat, true protein, lactose, and MUN by Fourier transform infrared spectroscopy using a MilkoScan FT+ (Foss Inc., Hillerød, Denmark) and SCC by flow cytometry in a Fossomatic FC (Foss Inc.). Subsamples of milk without preservative were collected concurrently, pooled using the same procedure described above, and stored at $-20^{\circ} \mathrm{C}$ until analyzed for EL and milk FA. Milk EL was extracted and hydrolyzed [ $\beta$-glucuronidase/ arylsulfatase from Helix pomatia (Roche-Diagnostics; Laval, QC, Canada)] according to procedures described previously (Gagnon et al., 2009). After extraction and hydrolysis, EL was analyzed colorimetrically in quadruplicate using a competitive commercial enzymatic immunoassay (assay kit no. 500520; Cayman Chemical Co., Ann Arbor, MI) that recognizes both enantiomeric forms of EL in a UV/visible spectrophotometer (Beckman Coulter Inc., Brea, CA) set at a wavelength of 405 nm. Milk samples were shipped to the Pennsylvania State University (Kevin Harvatine Laboratory) for FA analysis using GLC according to Rico and Harvatine (2013).

\section{Blood Sampling and Analyses}

Blood samples were collected from the coccygeal vein or artery approximately $4 \mathrm{~h}$ after the morning feeding 
on d 21 of each sampling week using 10-mL evacuated tubes containing $\mathrm{K}_{3}$-EDTA (Covidien, Minneapolis, $\mathrm{MN})$. After collection, tubes were kept on ice until processing. Samples were centrifuged $(3,300 \times g, 20 \mathrm{~min}$, $4^{\circ} \mathrm{C}$ ) and 2 aliquots of plasma were collected. The first aliquot was stored at $-80^{\circ} \mathrm{C}$ for determination of antioxidant enzymes activity, whereas the second one was stored at $-20^{\circ} \mathrm{C}$ for determination of plasma urea $\mathrm{N}$ (PUN) concentration. After thawing at room temperature, plasma samples were analyzed colorimetrically with a UV/Vis spectrophotometer (Beckman Coulter Inc.) for PUN (diacetyl monoxime method; Rosenthal, 1955) and catalase (assay kit \#707002; Cayman Chemical Co.) with wavelength set a $540 \mathrm{~nm}$, and for superoxide dismutase (SOD; assay kit \#706002, Cayman Chemical Co.) and glutathione peroxidase (GPx; assay kit no. 703102, Cayman Chemical Co.) at wavelengths of 450 and $340 \mathrm{~nm}$, respectively.

\section{Fecal and Urinary Sampling and Analyses}

Fecal and urinary samples were collected once daily on d $19(0700 \mathrm{~h}), 20(1200 \mathrm{~h})$, and $21(1800 \mathrm{~h})$ during each sampling week. Fecal grab samples were collected by stimulating defecation or directly from the rectum. After collection, fecal samples were stored in plastic bags at $-20^{\circ} \mathrm{C}$ and later dried in a forced-air oven $\left(55^{\circ} \mathrm{C}, 72 \mathrm{~h}\right)$. Next, samples were ground to pass through a 1-mm screen (Wiley mill) and pooled by cow based on dry weight over $3 \mathrm{~d}$ to obtain a single composite sample per cow per period. Fecal samples were analyzed for DM, ash, total N, NDF, ADF, and starch as described previously. Approximately $0.5 \mathrm{~g}$ of feces, feeds, and TMR was weighed into Ankom F57 bags (Ankom Technology), placed in 1 larger laundry bag, and inserted in the rumen of 1 ruminally cannulated lactating Jersey cow for $12 \mathrm{~d}$. After removal from the rumen, bags were rinsed with tap water and analyzed for $\mathrm{ADF}$ as described earlier. Indigestible $\mathrm{ADF}$ was used as an intrinsic marker to estimate fecal output of DM and apparent total-tract digestibility of nutrients (Cochran et al., 1986; Huhtanen et al., 1994).

Spot samples of urine were collected concurrently with fecal samples by stimulation of the pudendal nerve massaging the area bellow the vulva. After collection, urinary samples were immediately transported to the laboratory for processing. Subsamples of urine from each cow (2.8 mL/time point) were pooled over $3 \mathrm{~d}$ into $50-\mathrm{mL}$ centrifuge tubes containing $33.6 \mathrm{~mL}$ of $0.072 \mathrm{~N} \mathrm{H}_{2} \mathrm{SO}_{4}$ and stored at $-20^{\circ} \mathrm{C}$ until analysis. Urinary samples were thawed at room temperature and analyzed colorimetrically for creatinine (assay kit no. 500701; Cayman Chemical Co.) using a chromate mi- croplate reader set at a wavelength of $492 \mathrm{~nm}$ (Awareness Technology Inc., Palm City, FL), allantoin (Chen et al., 1992), uric acid (assay kit no. 1045-225; Stanbio Laboratory, Boerne, TX), and total N (micro-Kjeldahl analysis; AOAC, 1990; Dairy One Cooperative Inc.). Allantoin and uric acid were read at wavelengths of 522 and $520 \mathrm{~nm}$, respectively, on a UV/visible spectrophotometer (Beckman Coulter Inc.). Daily urinary volume was estimated from the urinary concentration of creatinine assuming a constant creatinine excretion rate of $0.212 \mathrm{mmol} / \mathrm{kg}$ of BW (Chizzotti et al., 2008). Urinary excretion of allantoin, uric acid, total purine derivatives (allantoin + uric acid), total $\mathrm{N}$, and urea $\mathrm{N}$ were calculated by multiplying the urinary volume by the concentration of each metabolite in urine.

\section{Statistical Analyses}

Data were analyzed using the MIXED procedure of SAS (SAS version 9.4; SAS Institute Inc., Cary, NC) according to a replicated $4 \times 4$ Latin square design. Squares were balanced for potential first-order carryover effects in subsequent periods (Williams, 1949; Kim and Stein, 2009), as each treatment immediately preceded and followed every other exactly once in each square. The model was fitted for all animal-related variables as

$$
\mathrm{Y}_{\mathrm{ijkl}}=\mu+\mathrm{S}_{\mathrm{i}}+\mathrm{P}_{\mathrm{j}}+\mathrm{C}_{\mathrm{k}(\mathrm{i})}+\mathrm{T}_{\mathrm{l}}+\mathrm{S} \times \mathrm{T}_{\mathrm{il}}+\mathrm{E}_{\mathrm{ijkl}},
$$

where $Y_{\mathrm{ijkl}}=$ dependent variable, $\mu=$ overall mean, $S_{i}=$ fixed effect of ith square, $P_{j}=$ fixed effect of jth period, $\mathrm{C}_{\mathrm{k}(\mathrm{i})}=$ random effect of kth cow within ith square, $\mathrm{T}_{1}=$ fixed effect of lth treatment, $\mathrm{S} \times \mathrm{T}_{\mathrm{il}}=$ interaction between ith square and lth treatment, and $\mathrm{E}_{\mathrm{ijkl}}=$ error term. Orthogonal polynomials were used to test linear, quadratic, and cubic effects in response to incremental dietary levels of LM in cows fed FM. All reported values are least squares means \pm standard error of the mean. Significance was declared at $P \leq$ 0.05 and trends at $0.05<P \leq 0.10$. Milk concentration of EL was transformed (natural log) before statistical analyses, but results presented herein were reported as adjusted mean values of quadruplicate runs on the original scale of measurements as done previously (Petit and Gagnon, 2009; Brito et al., 2015).

\section{RESULTS AND DISCUSSION}

\section{Feeds and Diets Nutritional Composition}

Sucrose was the predominant sugar found in LM, accounting for $77 \%$ of the total individual sugars measured chromatographically (Table 1). The concentrations of 
sucrose and total individual sugars in LM fed in the present study were similar to those obtained by Brito et al. (2017), but 38 and $49 \%$ lower, respectively, than values reported by Brito et al. (2015), thereby showing substantial variation in sugars content from source to source. As expected, the concentration of WSC, which was measured colorimetrically, was greatest in LM (Table 1). On average, the concentration of total individual sugars in LM analyzed chromatographically was $39 \%$ lower than that analyzed colorimetrically (Table 1 ), indicating that the analytical method used should be taken into account when making recommendations about optimum dietary levels of LM in dairy diets. The concentration of SDG in FM averaged $1.8 \%$ and was similar to the SDG content $($ mean $=1.66 \%)$ reported by Brito et al. (2015).

The dietary concentration of starch decreased from 9.6 to $1.64 \%$ and that of added individual sugars and WSC provided by LM increased from 0 to $4.95 \%$ and 0 to $8.08 \%$, respectively, when replacing GRC by incremental amounts of LM (Table 2). Total individual sugars and total WSC in the experimental diets increased from 3.90 to $8.63 \%$ and 4.02 to $12.9 \%$, respectively, with replacing GRC by increasing levels of LM (Table $2)$. The dietary concentrations of $\mathrm{CP}($ mean $=18.8 \%)$, $\mathrm{NDF}($ mean $=43.5 \%), \mathrm{ADF}($ mean $=28.6 \%)$, and $\mathrm{NE}_{\mathrm{L}}$ $($ mean $=1.56 \mathrm{Mcal} / \mathrm{kg}$ of DM $)$ were similar across diets (Table 2).

\section{Milk Enterolactone and Plasma Antioxidant Enzymes}

Only a cubic trend ( $P=0.08$; Figure 1$)$ was observed for milk EL despite the linear decrease in SDG intake when GRC was substituted with incremental amounts of LM in cows fed 15\% FM (Table 3), thus indicating no dietary effect on the content of EL in milk. Even though this cubic trend is difficult to explain biologically, the lack of a precursor-product relationship suggests that the ruminal output of EL seems to be more affected by the microbiota metabolism of SDG than by SDG supply. Milk EL yield did not differ and averaged $1.38,1.61,1.36$, and $1.52 \mathrm{mg} / \mathrm{d}$ when feeding $0,4,8$, or $12 \%$ LM, respectively (data not shown). We reported previously that, compared with GRC, LM increased the concentration and yield of milk EL in dairy cows fed grass hay plus $15 \%$ of the diet DM as FM (Brito et al., 2015), suggesting that LM may select for ruminal microorganisms with increased capacity to convert SDG to EL. Schogor et al. (2014) reported that Prevotella spp. were one of the main converters of SDG to secoisolariciresinol, a lignan-derived metabolite that is further metabolized to enterodiol and EL, presumably by other ruminal bacteria species. Prevotella species are also capable of utilizing starch, other noncellulosic polysaccharides, and simple sugars as energy sources, yielding succinate as the major end-product of ruminal fermentation (Purushe et al., 2010). However, ruminal samples were not collected in the present study, which limits our capacity to better understand the relationships among SDG supply, microbiota profile, and EL outputs in rumen and milk.

The plasma activities of the antioxidant enzymes GPx $($ mean $=119 \mathrm{nmol} / \mathrm{min}$ per milliliter $)$ and catalase $($ mean $=25.8 \mathrm{nmol} / \mathrm{min}$ per milliliter $)$ did not differ across treatments, whereas plasma SOD activity tended $(P=0.06)$ to respond cubically when replacing GRC by increasing amounts of LM in diets containing 15\% FM (Table 3). Despite similar cubic trend patterns observed for milk EL concentration and plasma SOD activity, the lack of significant effects in response to dietary changes for these 2 variables precludes any speculation about the capacity of EL to modulate the activity of antioxidant enzymes as shown previously (Rajesha et al., 2006; Côrtes et al., 2012). Brito et al. (2015) also observed no effects of FM (15\% of the diet DM) on the plasma activities of SDG and GPx in dairy cows fed GRC or LM as the sole supplemental NSC source.

\section{Production and Nutrient Digestibility}

Dry matter intake decreased linearly when replacing GRC by incremental amounts of LM in diets containing 15\% FM (Table 3). This drop in DMI may have been caused by excess sugars intake and the potential nega-

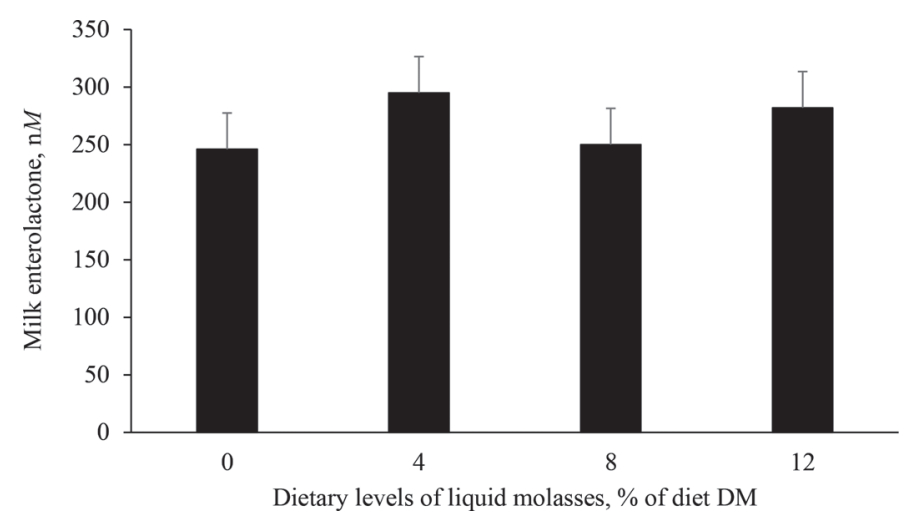

Figure 1. Effects of replacing ground corn with incremental amounts of sugarcane liquid molasses on milk concentration of enterolactone in Jersey cows fed flaxseed meal and low-starch diets (12:0, 8:4, 4:8, and 0:12 ground corn:liquid molasses dietary ratios). Data are presented as LSM \pm SEM. Orthogonal polynomials were used to test linear, quadratic, and cubic effects; significance was declared at $P$ $\leq 0.05$ and trends at $0.05<P \leq 0.10$. A trend $(P=0.08)$ for cubic effect was observed. 
tive effect on ruminal fermentation processes including decreased fiber digestibility. Broderick and Radloff (2004) reported a linear increase for DMI when highmoisture shelled corn was replaced (DM basis) by increasing amounts of dried molasses (0, 4, 8, and 12\%), and quadratic and cubic effects with increased LM (0, 3,6, and 9\%). Broderick and Radloff (2004) concluded that the overall optimum for total dietary sugars based on DMI and yields of milk and milk components was approximately $5 \%$ (2.4\% added sugars). In the present study, the dietary concentrations of added individual sugars and WSC exceeded the $2.4 \%$ threshold at 8 and $4 \%$ LM inclusion, respectively (Table 2). The 5\% total dietary sugars threshold was surpassed at $4 \%$ LM inclusion (Table 2) independent of the analytical method used. We noted marked differences in ingredient and nutritional composition comparing diets fed by Broderick and Radloff (2004) and those fed herein, which may help explain the discrepancy in DMI between these 2 studies in response to molasses supplementation. Furthermore, the range in total dietary sugars was wider in the present study (Table 2) than that (from 2.6 to $10 \%$ ) reported by Broderick and Radloff (2004) despite different analytical methods used in both experiments. It can be also hypothesized that interactions between molasses and ingredients in the basal diet may have affected DMI and ruminal fermentation processes, with more negative associative effects in low-starch diets based on mixed grass-legume baleage (present study) than in moderate- to- high-starch diets based on alfalfa and corn silage (Broderick and Radloff, 2004). In fact, Martel et al. (2011) demonstrated that replacing GRC with molasses (5\% of the diet DM) significantly increased ruminal $\mathrm{pH}$ and decreased total VFA concentration in late-lactation Holstein cows receiving highstarch diets. Brito et al. (2015) observed no depression on DMI when feeding $12 \%$ of the diet DM as LM $(7.4 \%$ added individual sugars) to Jersey cows offered a grass

Table 3. Effects of replacing ground corn with incremental amounts of sugarcane liquid molasses on production, milk composition, feed and milk $\mathrm{N}$ efficiencies, plasma concentrations of antioxidant enzymes, and BW change in Jersey cows fed flaxseed meal and low-starch diets

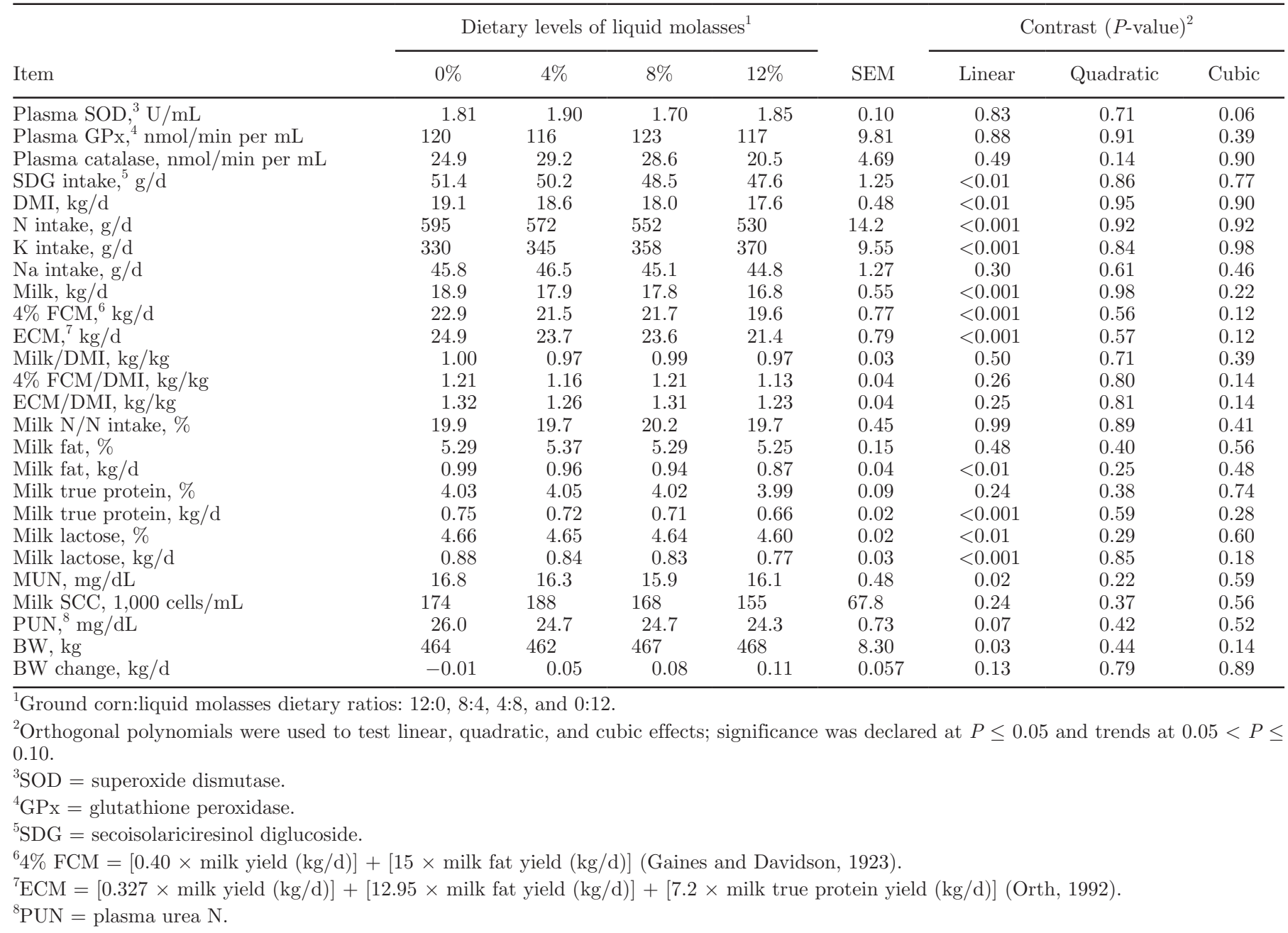


hay-based, low-starch diet, thus implying that forage sources may be more involved in triggering negative or positive associative effects between sugars and the basal diet than dietary starch concentration.

Yields of milk, 4\% FCM, and ECM all decreased linearly with replacing GRC by incremental amounts of LM in cows fed $15 \%$ FM, which are primarily explained by a linear decrease in DMI (Table 3). Broderick and Radloff (2004) reported that milk yield responded cubically or quadratically in dairy cows fed incremental amounts of dried molasses or LM, respectively. They also observed that yield of 3.5\% FCM tended to respond quadratically or decreased linearly in cows receiving dried or LM, respectively (Broderick and Radloff, 2004). In contrast, Baurhoo and Mustafa (2014) reported no effects on yields of milk, 4\% FCM, and ECM when high-moisture corn was replaced by increasing amounts of dried molasses $(0,3$, and $6 \%$ of the diet DM) in dairy cows offered alfalfa silage-based diets. Brito et al. (2015) observed no effect on milk yield when comparing GRC versus LM as the sole NSC supplemental source, but both 4\% FCM and ECM yields decreased significantly in LM cows. Recently, we reported that yields of milk, $4 \% \mathrm{FCM}$, and ECM were not changed in grazing dairy cows fed GRC or LM as the sole NSC supplemental source (Brito et al., 2017). Collectively, these results suggest that differences in the ingredient composition of the basal diet, level of molasses fed, forage source, and forage-to-concentrate ratio, among other factors, may be responsible for the inconsistent responses on yields of milk, FCM, and ECM across the literature. Feed efficiency, expressed as milk yield per DMI (mean $=0.98 \mathrm{~kg} / \mathrm{kg}), 4 \% \mathrm{FCM}$ yield per DMI $($ mean $=1.18$ $\mathrm{kg} / \mathrm{kg}$ ), or ECM yield per DMI (mean $=1.28 \mathrm{~kg} / \mathrm{kg}$ ), was not affected by feeding LM at expense of GRC (Table 3). Similarly, milk N efficiency did not change and averaged $19.9 \%$ across treatments.

The concentrations of milk fat and true protein were not affected by dietary levels of LM, whereas lactose content tended to decrease linearly $(P=0.06)$ in cows offered 15\% FM (Table 3). Yields of milk fat, true protein, and lactose followed milk yield and decreased linearly (Table 3). We noted inconsistent results in milk component concentrations and yields in response to dried or LM supplementation. Broderick and Radloff (2004) reported quadratic and cubic effects for yields of milk fat and protein, respectively, in cows fed increasing amounts of dried molasses. Broderick and Radloff (2004) also observed linear, quadratic, and cubic effects for milk protein concentration, and a quadratic effect for milk protein yield when replacing high-moisture shelled corn with LM. However, Baurhoo and Mustafa (2014) reported no effects on concentrations and yields of milk fat, protein, and lactose by substituting high- moisture corn with different levels of dried molasses. When GRC or LM was fed as the sole supplemental NSC, yield of milk fat decreased in dairy cows fed grass hay (Brito et al., 2015), whereas concentrations and yields of milk fat, true protein, and lactose did not change in those fed pasture (Brito et al., 2017).

The concentration of MUN decreased linearly when GRC was replaced by LM (Table 3). Because the dietary concentration of $\mathrm{CP}$ was relatively similar across treatments (Table 2), a linear decrease in $\mathrm{N}$ intake (Table 3) appears to explain, at least partially, the observed decrease in MUN. Alternatively, Bannink et al. (1999) reported that intake and urinary excretion of $\mathrm{K}, \mathrm{Na}$, and $\mathrm{N}$ explained, respectively, 85.8 and $89.8 \%$ of the variance when regressed against urinary volume in lactating dairy cows. Eriksson and Rustas (2014) observed a positive linear relationship between $\mathrm{K}$ intake and urinary volume and a negative linear relationship between K intake and MUN in dairy cows. Spek et al. (2012) showed that feeding incremental amounts of $\mathrm{Na}$ to dairy cows increased linearly the urinary volume and total urinary $\mathrm{N}$ excretion, and decreased linearly MUN concentration. In the current study, whereas the intake of $\mathrm{K}$ (Table 3) and urinary volume (Table 4) increased linearly with substituting GRC by LM, that of Na decreased linearly (Table 3). Our results suggest that $\mathrm{K}$ was likely more involved in the linear decrease of MUN than Na, which is not surprising, as the difference in $\mathrm{K}$ intake was much larger compared with that of $\mathrm{Na}$ intake across treatments. According to Spek et al. (2012) and Eriksson and Rustas (2014), elevated $\mathrm{Na}$ and $\mathrm{K}$ intake leads to increased renal glomerular filtration rate and a temporary increase in the urinary excretion of urea N, ultimately dropping both MUN and PUN. The concentration of PUN followed that of MUN and tended $(P=0.07)$ to decrease linearly (Table 3).

The apparent total-tract digestibility of starch responded linearly and quadratically, whereas that of CP decreased linearly with feeding incremental amounts of LM (Table 4). No treatment effects were observed for $\mathrm{DM}, \mathrm{OM}, \mathrm{NDF}$, and ADF apparent total-tract digestibilities (Table 4). Despite linear and quadratic effects for starch digestibility, the actual differences across treatments were too small and not biologically significant. It is also important to note that starch digestibility averaged $99.9 \%$ among treatments, which is probably explained by the low dietary concentration of starch $($ mean $=5.7 \%$; Table 2$)$ and consequent low starch intake (data not shown). The effect of replacing corn grain by dried or LM on apparent total-tract digestibility of nutrients is not consistent based on previous research. Broderick and Radloff (2004) reported linear increases for the total-tract digestibilities of DM, OM, NDF, and 
ADF when feeding incremental amounts of dried molasses, as well as quadratic and cubic effects for NDF and ADF digestibilities in cows offered increasing levels of LM. In contrast, Baurhoo and Mustafa (2014) observed no effect of different dietary levels of dried molasses on apparent total-tract digestibilities of DM, OM, NDF, $\mathrm{CP}$, and gross energy. When GRC or LM was fed as the sole NSC supplemental source to lactating dairy cows, $\mathrm{CP}$ digestibility decreased in LM cows, but no treatment effects were observed for DM, OM, NDF, and ADF digestibilities (Brito et al., 2015). Broderick et al. (2008) reported that the apparent ruminal digestibility of $\mathrm{N}$ reduced linearly when sucrose was increased from 0 to $7.5 \%$ of diet DM at the expense of corn starch, suggesting a similar response in the present study. Alternatively, the linear drop in CP digestibility observed herein may have been caused by decreased dilution of fecal metabolic $\mathrm{N}$ due to lowered $\mathrm{N}$ intake (Table 3) as suggested by Kauffman and St-Pierre (2001). When fecal $\mathrm{N}$ excretion was corrected for metabolic N, which was estimated assuming an excretion rate of $5.5 \mathrm{~g} /$ $\mathrm{kg}$ of DMI in Jersey cows (Kauffman and St-Pierre, 2001), the linear response in CP digestibility went from significant (Table 4$)$ to a trend $(P=0.06$; data not shown). Overall, discrepant results across the literature regarding the effects of dried or LM supplementation on apparent total-tract digestibility of nutrients may be related to differences in dietary levels of sugars among other potential factors, as discussed earlier.

The urinary excretion of total $\mathrm{N}$ decreased linearly with substituting GRC with increasing amounts of LM, which is consistent with the linear decrease in urinary volume (Table 4). In contrast, no treatment effects were observed when the urinary excretion of total $\mathrm{N}$ was expressed as a proportion of $\mathrm{N}$ intake (mean $=42 \%$ ). Similarly, the urinary excretion of urea $\mathrm{N}$ expressed in quantity $($ mean $=121 \mathrm{~g} / \mathrm{d})$, as a proportion of total urinary $\mathrm{N}$ (mean $=54 \%$ ), or as a proportion of $\mathrm{N}$ intake (mean $=22 \%$ ) was not affected by treatments (Table 4 ). The urinary excretion of allantoin (mean = $164 \mathrm{mmol} / \mathrm{d}$ ) and total purine derivatives (mean $=202$ $\mathrm{mmol} / \mathrm{d}$ ) also did not differ significantly among treatments (Table 4); however, the urinary excretion of uric acid tended $(P=0.08)$ to respond cubically in cows fed LM at expense of GRC (Table 4). Interestingly, the urinary excretion of uric acid followed a cubic pattern very similar compared with that observed for milk EL (Figure 1), with cows fed 4\% LM showing the greatest values for these 2 variables. Uric acid is a purine derivative used as an indirect marker to estimate microbial protein synthesis, thus consistent with the response in milk EL. It is well established that FM-SDG is converted primarily to EL by the ruminal microbiota in ruminants (Gagnon et al., 2009; Zhou et al., 2009).

Table 4. Effects of replacing ground corn with incremental amounts of sugarcane liquid molasses on apparent total-tract digestibility of nutrients and urinary excretion of nitrogenous metabolites in Jersey cows fed flaxseed meal and low-starch diets

\begin{tabular}{|c|c|c|c|c|c|c|c|c|}
\hline Item & \multicolumn{4}{|c|}{ Dietary levels of liquid molasses ${ }^{1}$} & SEM & \multicolumn{3}{|c|}{ Contrast $(P \text {-value })^{2}$} \\
\hline \multicolumn{9}{|c|}{ Apparent total-tract digestibility } \\
\hline $\mathrm{OM}, \%$ of $\mathrm{OM}$ intake & 72.7 & 71.2 & 72.1 & 72.1 & 0.64 & 0.71 & 0.18 & 0.22 \\
\hline NDF, $\%$ of NDF intake & 64.7 & 64.1 & 65.0 & 65.2 & 0.93 & 0.56 & 0.64 & 0.59 \\
\hline $\mathrm{ADF}, \%$ of $\mathrm{ADF}$ intake & 67.1 & 66.5 & 67.3 & 66.8 & 0.99 & 0.98 & 0.97 & 0.55 \\
\hline \multicolumn{9}{|l|}{ Urinary volume and excretion } \\
\hline Urine, L/d & 24.3 & 24.9 & 26.9 & 25.8 & 0.79 & 0.02 & 0.16 & 0.08 \\
\hline Creatinine, $\mathrm{m} M$ & 4.19 & 4.10 & 3.84 & 3.88 & 0.11 & $<0.01$ & 0.45 & 0.24 \\
\hline Uric acid, $\mathrm{mmol} / \mathrm{d}$ & 36.9 & 40.1 & 35.4 & 37.2 & 2.55 & 0.63 & 0.73 & 0.08 \\
\hline Allantoin, $\mathrm{mmol} / \mathrm{d}$ & 154 & 172 & 168 & 163 & 12.1 & 0.65 & 0.30 & 0.70 \\
\hline Total $\mathrm{PD}, 3 \mathrm{mmol} / \mathrm{d}$ & 191 & 212 & 204 & 200 & 13.1 & 0.71 & 0.31 & 0.51 \\
\hline PD:creatinine ratio ${ }^{4}$ & 1.93 & 2.14 & 2.05 & 2.15 & 0.13 & 0.33 & 0.68 & 0.41 \\
\hline
\end{tabular}




\section{Milk FA Profile}

Milk proportions of 8:0, 10:0, 12:0, 18:0, and 20:0 decreased linearly, whereas 16:0 increased linearly in cows fed incremental amounts of LM and $15 \% \mathrm{FM}$ (Table 5). Intake of 18:0 decreased linearly $(P<0.01$; data not shown), which is consistent with the linear reduction in milk 18:0. Furthermore, $\Sigma$ 18C FA also decreased linearly (Table 5), indicating less uptake of preformed 18:0 from plasma by the mammary gland, possibly as a result of reduced 18:0 intake. Similarly, we observed that the milk proportion of 18:0 decreased in dairy cows fed grass hay (Brito et al., 2015) or pasture (Brito et al., 2017) supplemented with LM versus GRC. In contrast, although intake of 16:0 reduced linearly $(P$ $<0.01$; data not shown), the milk proportion of 16:0 increased linearly (Table 5), suggesting enhanced de novo synthesis of 16:0 in the mammary gland or uptake from plasma; in fact, $\Sigma 16 \mathrm{C}$ also increased linearly in the present study (Table 5). Brito et al. (2015) observed a similar decoupled response between 16:0 intake and milk 16:0 in cows fed LM versus GRC.

Milk proportions of the branched-chain FA iso 14:0 and iso 16:0 decreased linearly, whereas iso 15:0 and iso 17:0 increased linearly in cows fed incremental amounts of LM (Table 5). Milk proportion of the odd-chain FA 15:0 increased linearly and quadratically, with the greatest proportion of this FA observed in the diet containing 12\% LM (Table 5). Similarly, the proportion of 17:0 in milk increased linearly and tended $(P=0.07)$ to respond quadratically when GRC was substituted with LM. The $\Sigma$ odd-chain FA followed the milk proportions of 15:0 and 17:0 and increased linearly and quadratically (Table 5). In our previous research, milk proportions of 15:0 and 17:0 were also greater in cows fed LM compared with GRC (Brito et al., 2015, 2017). It is well known that milk odd- and branched-chain FA originate primarily from ruminal microbiota cells (Fievez et al., 2012). Therefore, data from the present study appear to indicate that LM may favor the growth of ruminal microbes enriched in iso 15:0, iso 17:0, 15:0, and 17:0, while inhibiting those enriched in iso 14:0 and iso 16:0.

Milk proportions of cis-9 18:1, cis-12 18:1, trans 6-8 18:1, trans-9 18:1, trans-12 18:1, trans-15 18:1, cis9,cis-12 18:2, and $\Sigma$ cis-18:1 FA all decreased linearly, while trans-10 18:1 tended $(P=0.08)$ to reduce linearly when cows were fed incremental amounts of LM at expense of GRC (Table 5). Intake of cis-9 18:1 ( $P$ $<0.001)$ and cis-9,cis-12 18:2 $(P<0.01)$ decreased linearly (data not shown), thus explaining the linear reductions in milk cis-9 18:1 and cis-9,cis-12 18:2. The trans-11-to-trans-10 ratio also decreased linearly, indicating that ruminal biohydrogenation pathways were shifted toward trans-11 18:1 rather than trans-10 18:1, which agrees with Martel et al. (2011) and our previous research (Brito et al., 2017). Although the milk proportion of cis-9,cis-12,cis-15 18:3 increased linearly as LM replaced GRC (Table 5), intake of this FA decreased linearly $(P<0.01$; data not shown $)$, thus suggesting that cis-9,cis-12,cis-15 18:3 was less biohydrogenated in the rumen. According to Martel et al. (2011), ruminal protozoa may slow down FA biohydrogenation by maintaining an intracellular pool of FA away from biohydrogenating bacteria. However, the literature is inconsistent regarding whether dietary sugar promotes or inhibits growth of ruminal protozoa (Martel et al., 2011), possibly because of the heterogeneous nature of these microbes (Oelker et al., 2009). Milk proportion of cis-9,trans-11 18:2 increased linearly despite a numerical increase in trans-11 18:1 when feeding increasing levels of LM (Table 5). The $\Delta^{9}$-desaturase index for the for the trans-11 18:1/cis-9,trans-11 18:2 pair increased linearly (Table 5), indicating that elevated cis-9,trans-11 18:2 resulted from endogenous synthesis via the $\Delta^{9}$-desaturase enzyme using trans-11 18:1 as substrate (Griinari et al., 2000).

\section{CONCLUSIONS}

Despite a linear decrease in SDG intake, the concentration of EL in milk tended to respond cubically when replacing GRC by incremental amounts of LM in cows fed $15 \%$ of the diet DM as FM, thus contradicting our first hypothesis. Our second hypothesis, that production and milk $\mathrm{N}$ efficiency would be improved due to a better balance between RDP and fermentable energy supply when substituting GRC with LM, was also rejected. Our third hypothesis was partly confirmed, as the linear decreases in cis-9 18:1 and cis-9,cis-12 18:2 in milk were consistent with decreased intake of these FA in cows fed LM at expense of GRC. However, a decoupled response between milk cis-9,cis-12,cis-15 18:3 and intake of this FA was also observed. Further research is needed to better understand how FM-SDG is affected by changes in diversity and function of the ruminal microbiome, and how potential interactions between different forage sources and dietary sugars affect production and $\mathrm{N}$ utilization in dairy cows.

\section{ACKNOWLEDGMENTS}

Partial funding was provided by the New Hampshire Agricultural Experiment Station (Durham, NH; Scientific Contribution Number 2762). This work was further supported by the USDA-National Institute of Food and Agriculture-Organic Agriculture Research and Extension Initiative (Project Number NHW-201101950; Project Accession Number 226410, Washington, 
Table 5. Effects of replacing ground corn with incremental amounts of sugarcane liquid molasses on the milk proportions of SFA and UFA in Jersey cows fed flaxseed meal and low-starch diets

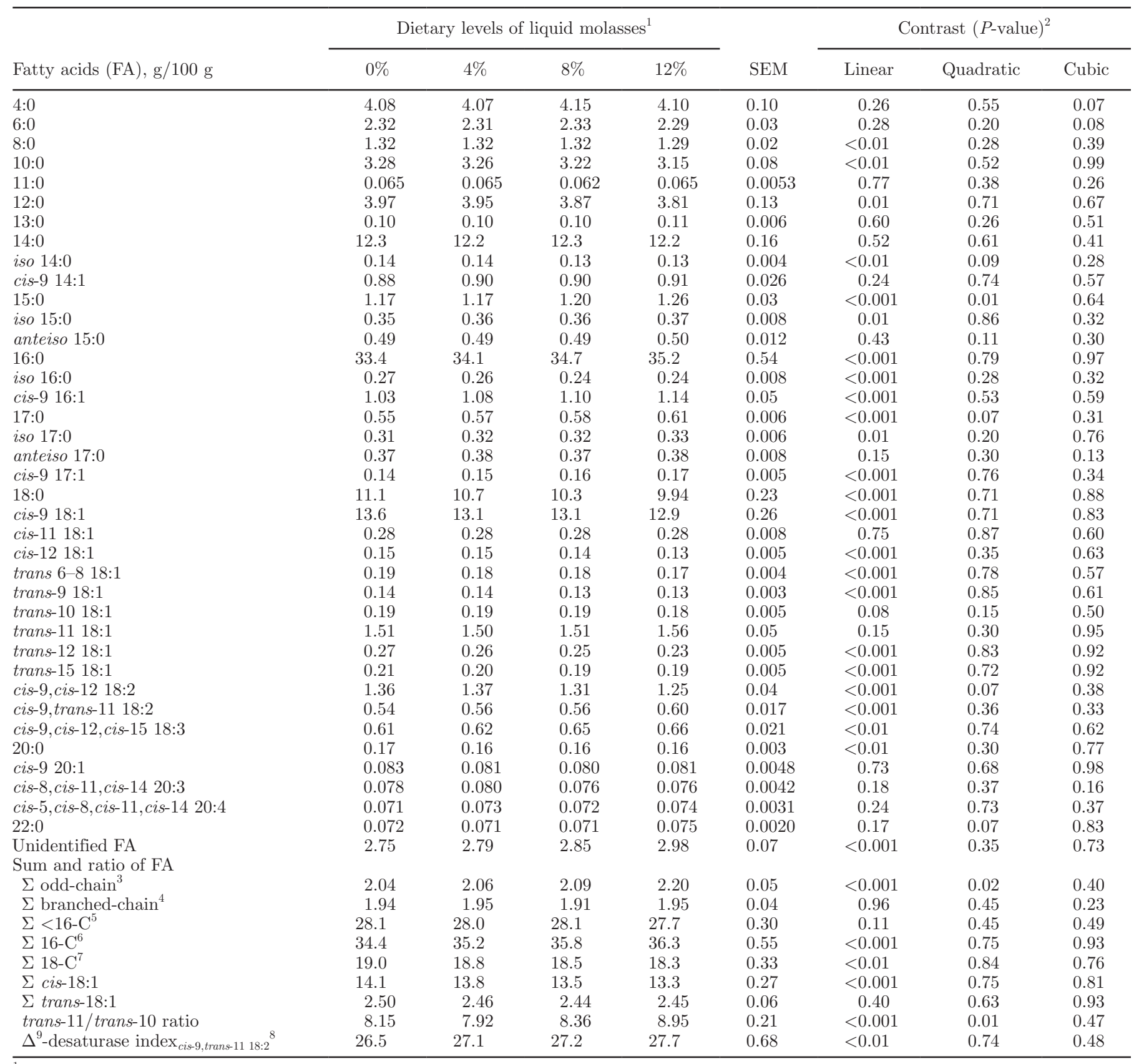

${ }^{1}$ Ground corn:liquid molasses dietary ratios: 12:0, 8:4, 4:8, and 0:12.

${ }^{2}$ Orthogonal polynomials were used to test linear, quadratic, and cubic effects; significance was declared at $P \leq 0.05$ and trends at $0.05<P \leq$ 0.10 .

${ }^{3} \Sigma$ odd-chain FA $=11: 0+13: 0+15: 0+17: 0+$ cis-9 17:1.

${ }^{4} \Sigma$ branched-chain $\mathrm{FA}=$ iso $14: 0+$ iso $15: 0+$ anteiso $15: 0+$ iso $16: 0+$ iso $17: 0+$ anteiso $17: 0$.

${ }^{5} \Sigma<16$-C FA (originate from de novo synthesis in the mammary gland) $=4: 0+6: 0+8: 0+10: 0+12: 0+14: 0+$ cis-9 14:1.

${ }^{6} \Sigma$ 16-C FA (originate from de novo synthesis in the mammary gland and extraction from plasma) $=16: 0+$ cis-9 16:1.

${ }^{7} \Sigma$ 18-C FA (originate from plasma extraction) $=18: 0+$ all $18-\mathrm{C}$ UFA.

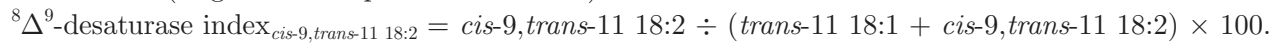


DC) and Hatch Multistate NC-2042 (Project Number NH00616-R; Project Accession Number 1001855). Gratitude is extended to Coordenação de Aperfeiçoamento de Pessoal de Nível Superior (CAPES, Brasília, DF, Brazil) and Conselho Nacional de Desenvolvimento Científico e Tecnológico (CNPq) (Brasília, DF, Brazil) for awarding scholarships to first author Caren $\mathrm{P}$. Ghedini and co-author Daiane C. Moura, respectively. Authors also thank the post-doctorate student Simone F. Reis (University of New Hampshire) and graduate student André B. D. Pereira (University of New Hampshire; current affiliation: Purina Animal Nutrition LLC, Shoreview, MN) for support during feeding and samples collection. Gratitude is extended to the University of New Hampshire Burley-Demeritt Organic Dairy Research Farm manager Nicole Guindon and her staff for animal care and overall research support.

\section{REFERENCES}

Adolphe, J. L., S. J. Whiting, B. H. J. Juurlink, L. U. Thorpe, and J. Alcorn. 2010. Health effects with consumption of the flax lignan secoisolariciresinol diglucoside. Br. J. Nutr. 103:929-938.

AOAC. 1990. Official Methods of Analysis. 15th ed. AOAC, Arlington, VA.

AOAC International. 2016. Official Methods of Analysis, 20th ed. AOAC International, Gaithersburg, MD.

Bannink, A., H. Valk, and A. M. Van Vuuren. 1999. Intake and excretion of sodium, potassium, and nitrogen and the effects on urine production by lactating dairy cows. J. Dairy Sci. 82:1008-1018.

Baurhoo, B., and A. Mustafa. 2014. Short communication: Effects of molasses supplementation on performance of lactating cows fed high-alfalfa silage diets. J. Dairy Sci. 97:1072-1076.

Brito, A. F., H. V. Petit, A. B. D. Pereira, K. J. Soder, and S. Ross. 2015. Interactions of corn meal or molasses with a soybean-sunflower meal mix or flaxseed meal on production, milk fatty acid composition, and nutrient utilization in dairy cows fed grass haybased diets. J. Dairy Sci. 98:443-457.

Brito, A. F., K. J. Soder, P. Y. Chouinard, S. F. Reis, S. Ross, M. D. Rubano, and M. D. Casler. 2017. Production performance and milk fatty acid profile in grazing dairy cows offered ground corn or liquid molasses as the sole supplemental nonstructural carbohydrate source. J. Dairy Sci. 100:8146-8160.

Broderick, G. A., N. D. Luchini, S. M. Reynal, G. A. Varga, and V. A Ishler. 2008. Effect on production of replacing dietary starch with sucrose in lactating dairy cows. J. Dairy Sci. 91:4801-4810.

Broderick, G. A., and W. J. Radloff. 2004. Effect of molasses supplementation on the production of lactating dairy cows fed diets based on alfalfa and corn silage. J. Dairy Sci. 87:2997-3009.

Chen, X. B., Y. K. Chen, M. F. Franklin, E. R. Orskov, and W. J. Shand. 1992. The effect of feed intake and body weight on purine derivative excretion and microbial protein supply in sheep. J. Anim. Sci. 70:1534-1542.

Chizzotti, M. L., S. C. Valadares Filho, R. F. D. Valadares, F. H. M. Chizzotti, and L. O. Tedeschi. 2008. Determination of creatinine excretion and evaluation of spot urine sampling in Holstein cattle. Livest. Sci. 113:218-225.

Cochran, R. C., D. C. Adams, J. D. Wallace, and M. L. Galyean. 1986. Predicting digestibility of different diets with internal markers: evaluation of four potential markers. J. Anim. Sci. 63:1476-1483.

Côrtes, C., M.-F. Palin, N. Gagnon, C. Benchaar, P. Lacasse, and H. V. Petit. 2012. Mammary gene expression and activity of antioxidant enzymes and concentration of the mammalian lignan enterolactone in milk and plasma of dairy cows fed flax lignans and infused with flax oil in the abomasum. Br. J. Nutr. 108:1390-1398.
Eriksson, T., and B.-O. Rustas. 2014. Effects on milk urea concentration, urine output, and drinking water intake from incremental doses of potassium bicarbonate fed to mid-lactation dairy cows. J. Dairy Sci. 97:4471-4484.

Fievez, V., E. Colman, J. M. Castro-Montoya, I. Stefanov, and B. Vlaeminck. 2012. Milk odd- and branched-chain fatty acids as biomarkers of rumen function-An update. Anim. Feed Sci. Technol. 172:51-65.

Gagnon, N., C. Côrtes, D. da Silva, R. Kazama, C. Benchaar, G. dos Santos, L. Zeoula, and H. V. Petit. 2009. Ruminal metabolism of flaxseed (Linum usitatissimum) lignans to the mammalian lignan enterolactone and its concentration in ruminal fluid, plasma, urine and milk of dairy cows. Br. J. Nutr. 102:1015-1023.

Gaines, W. L., and F. A. Davidson. 1923. Relation Between Percentage Fat Content and Yield of Milk. Univ. Illinois Agric. Exp. Stn. Bull. 245. Univ. Illinois, Urbana.

Gaya, P., M. Medina, A. Sánchez-Jiménez, and J. M. Landete. 2016. Phytoestrogen metabolism by adult human gut microbiota. Molecules 21:1034-1050.

Griinari, J. M., B. A. Corl, S. H. Lacy, P. Y. Chouinard, K. V. V Nurmela, and D. E. Bauman. 2000. Conjugated linoleic acid is synthesized endogenously in lactating dairy cows by $\Delta 9$-desaturase. J. Nutr. 130:2285-2291.

Hall, M. B., W. H. Hoover, J. P. Jennings, and T. K. M. Webster. 1999. A method for partitioning neutral detergent soluble carbohydrates. J. Sci. Food Agric. 79:2079-2086.

Högger, P. 2013. Nutrition-derived bioactive metabolites produced by gut microbiota and their potential impact on human health. Nutr. Med. 1:1-32.

Huhtanen, P., K. Kaustell, S. Jaakkola, E. M. Aitchison, M. Gill, and M. Dhanoa. 1994. The use of internal markers to predict total digestibility and duodenal flow of nutrients in cattle given six different diets. Anim. Feed Sci. Technol. 48:211-227.

Imran, M., N. Ahmad, F. M. Anjum, M. K. Khan, Z. Mushtaq, M. Nadeem, and S. Hussain. 2015. Potential protective properties of flax lignan secoisolariciresinol diglucoside. Nutr. J. 14:71-77.

Kauffman, A. J., and N. R. St-Pierre. 2001. The relationship of milk urea nitrogen to urine nitrogen excretion in Holstein and Jersey cows. J. Dairy Sci. 84:2284-2294.

Kim, B. G., and H. H. Stein. 2009. A spreadsheet program for making a balanced Latin square design. Rev. Colomb. Cienc. Pecu. 22:591-596.

Martel, C. A., E. C. Titgemeyer, L. K. Mamedova, and B. J. Bradford. 2011. Dietary molasses increases ruminal $\mathrm{pH}$ and enhances ruminal biohydrogenation during milk fat depression. J. Dairy Sci 94:3995-4004

Muir, A. D., and N. D. Westcott. 2000. Quantification of the lignan secoisolariciresinol diglucoside in baked goods containing flax seed or flax meal. J. Agric. Food Chem. 48:4048-4052.

NRC. 2001. Nutrient Requirements of Dairy Cattle. 7th rev. ed. Natl. Acad. Sci., Washington, DC.

Oelker, E. R., C. Reveneau, and J. L. Firkins. 2009. Interaction of molasses and monensin in alfalfa hay- or corn silage-based diets on rumen fermentation, total tract digestibility, and milk production by Holstein cows. J. Dairy Sci. 92:270-285.

Orth, R. 1992. Sample Day and Lactation Report. DHIA 200 FactSheet A-2. Mid-States DRPC, Ames, IA

Petit, H. V., and N. Gagnon. 2009. Milk concentrations of the mammalian lignans enterolactone and enterodiol, milk production, and whole tract digestibility of dairy cows fed diets containing different concentrations of flaxseed meal. Anim. Feed Sci. Technol. 152:103-111.

Purushe, J., D. E. Fouts, M. Morrison, B. A. White, R. I. Mackie, P. M. Coutinho, B. Henrissat, and K. E. Nelson. 2010. Comparative genome analysis of Prevotella ruminicola and Prevotella bryantii: Insights into their environmental niche. Microb. Ecol. 60:721-729.

Rajesha, J., K. N. C. Murthy, M. K. Kumar, B. Madhusudhan, and G. A. Ravishankar. 2006. Antioxidant potentials of flaxseed by in vivo model. J. Agric. Food Chem. 54:3794-3799.

Rico, D. E., and K. J. Harvatine. 2013. Induction of and recovery from milk fat depression occurs progressively in dairy cows switched 
between diets that differ in fiber and oil concentration. J. Dairy Sci. 96:6621-6630.

Rosenthal, H. L. 1955. Determination of urea in blood and urine with diacetyl monoxime. Anal. Chem. 27:1980-1982.

Schogor, A. L. B., S. A. Huws, G. T. D. Santos, N. D. Scollan, B. D. Hauck, A. L. Winters, E. J. Kim, and H. V. Petit. 2014. Ruminal Prevotella spp. may play an important role in the conversion of plant lignans into human health beneficial antioxidants. PLoS One 9:e87949.

Siverson, A., C. F. Vargas-Rodriguez, and B. J. Bradford. 2014. Short communication: Effects of molasses products on productivity and milk fatty acid profile of cows fed diets high in dried distillers grains with solubles. J. Dairy Sci. 97:3860-3865.

Soder, K. J., K. Hoffman, L. E. Chase, and M. D. Rubano. 2012. Case study: Molasses as the primary energy supplement on an organic grazing dairy farm. Prof. Anim. Sci. 28:234-243.

Spek, J. W., A. Bannink, G. Gort, W. H. Hendriks, and J. Dijkstra. 2012. Effect of sodium chloride intake on urine volume, urinary urea excretion, and milk urea concentration in lactating dairy cattle. J. Dairy Sci. 95:7288-7298.
Sukhija, P. S., and D. L. Palmquist. 1988. Rapid method for determination of total fatty acid content and composition of feedstuffs and feces. J. Agric. Food Chem. 36:1202-1206.

Thompson, L. U., P. Robb, M. Serraino, and F. Cheung. 1991. Mammalian lignan production from various foods. Nutr. Cancer 16:4352 .

USDA. 2010. Livestock living conditions. Section 205.239. Accessed Aug. 4, 2017. https://www.ecfr.gov/cgi-bin/text-idx?SID= 38fb700cb79331adaec0a1e05477134f\&mc $=$ true\&node $=\mathrm{se} 7.3 .205$ -1239\&rgn=div8.

Van Soest, P. J., J. B. Robertson, and B. A. Lewis. 1991. Methods for dietary fiber, neutral detergent fiber, and nonstarch polysaccharides in relation to animal nutrition. J. Dairy Sci. 74:3583-3597.

Williams, E. J. 1949. Experimental designs balanced for the estimation of residual effects of treatments. Aust. J. Sci. Res., A 2:149-168.

Zhou, W., G. Wang, Z. Han, W. Yao, and W. Zhu. 2009. Metabolism of flaxseed lignans in the rumen and its impact on ruminal metabolism and flora. Anim. Feed Sci. Technol. 150:18-26. 